\title{
HABITAÇÃO E SUSTENTABILIDADE EM ÁREAS DE FRAGILIDADE AMBIENTAL
}

\author{
Josinês Barbosa Rabelo ${ }^{1}$
}

RESUMO: O artigo apresenta uma reflexão habitação e sustentabilidade ambiental em áreas de fragilidade ambiental tendo como campo empírico processo de urbanização da comunidade llha de Deus, situada no estuário do Pina, no Recife. As populações pobres estão mais expostas aos riscos ambientais decorrentes da localização das suas moradias e pela falta de saneamento. Existe uma correlação entre pobreza e doença associada à falta de serviços essenciais. Esse quadro tem impulsionado os movimentos sociais a buscar alternativas de enfrentamento da superação da desigualdade social e pela justiça ambiental através da luta pelo direito à moradia. A metodologia baseia-se no levantamento de dados junto ao poder público, outras pesquisas realizadas sobre a llha de Deus e entrevistas com lideranças comunitárias. Os resultados mostram a alta vulnerabilidade socioambiental da comunidade e a intervenção do poder público de forma intersetorializada na perspectiva de melhorar as condições socioambientais da comunidade.

Palavras-chave: Habitação. Sustentabilidade. Manguezal.

\section{INTRODUÇÃO}

A urbanização brasileira impulsionou a tendência evolutiva da ocupação e uso do território das áreas urbanas, o que contribuiu para o Brasil tornar-se predominantemente um país urbano. Um crescente número de centros urbanos de vários tamanhos e grandes

1 Doutoranda em Desenvolvimento Urbano pela Universidade Federal de Pernambuco. E-mail: josie.rabelo@gmail.com 
aglomerações metropolitanas surgiram. Essas aglomerações foram registrando macrocefalias relativas desenvolvendo cidades milionárias, intermediárias e cidades locais, todas, adotando um modelo geográfico de crescimento espraiado, sem medidas que é a causa e é efeito da especulação (SANTOS, 1996).

Esse processo provocou uma grande concentração de pessoas em um número reduzido de regiões metropolitanas e em grandes cidades, a exemplo do Rio de Janeiro e São Paulo, bem como Salvador, Recife e Fortaleza que são focos importantes de concentração demográfica e de expansão urbana no Nordeste e que vêm ganhando um papel importante na dinâmica urbano-industrial nos últimos anos.

Essa dinâmica apresenta impactos que se expressam no aumento da poluição de rios, lagos, decorrentes da ausência de infraestrutura de saneamento; pressão urbana sobre as áreas com cobertura vegetal remanescente de Mata Atlântica, onde estão localizadas as fontes de águas que abastecem as cidades, entre outros. Esses problemas têm cada vez mais exigido do poder público investimentos em saneamento e habitação e evidenciam a complexidade dos processos de transformação socioambiental, espacial, ocupacional que é socialmente diversificada, segmentada e desigual.

Desse modo, pode-se dizer que a cidade é o lócus de contradições fruto do modelo econômico capitalista. A urbanização e os interesses do capital imobiliário aliado a deficiência do Estado de regulação e redistribuição contribuiu para a conformação dessa desigualdade e para a emergência de dois graves problemas: a exclusão social e a especulação imobiliária. Pode-se dizer que a urbanização e o desenvolvimento não asseguraram condições de trabalho e de subsistência para a população e ampliou as carências sociais e de serviços públicos, bem como a deterioração ambiental e o estrangulamento da infraestrutura das cidades. A distribuição da população nas áreas urbanas evidencia a tendência de urbanização no entorno de biomas que vêm sofrendo pressões da ocupação humana.

Diante dos problemas ambientais do mundo globalizado, o relatório Bruntland ${ }^{2}$ traz à tona a necessidade de uma nova relação ser humano-meio ambiente, bem como as relações

\footnotetext{
${ }^{2}$ Este relatório é o resultado do trabalho da comissão da ONU World Comission on Environment and Development presidida por Gro Harlem Brundtlandt e Mansour Khalid, ficou conhecido como Nosso Futuro Comum, 1987.
} 
estabelecidas entre estilos de desenvolvimento e qualidade dos sistemas naturais, sugerindo uma conciliação com as questões ambientais. Aponta ainda como desafio para as gestões públicas, a elaboração de estratégias de desenvolvimento que considere a relação entre pobreza e desenvolvimento e ressalta que é a pobreza causa e efeito da deterioração ambiental.

O relatório apresenta o conceito de desenvolvimento sustentável tendo como definição aquele que satisfaz as necessidades das gerações presentes sem comprometer as possibilidades das futuras gerações satisfazerem as suas. Um dos princípios do conceito de desenvolvimento sustentável é a sua base ecológica. A conservação dos ecossistemas e dos recursos naturais é uma condição fundamental para o desenvolvimento.

As reflexões do relatório de Bruntland levantaram a questão da sustentabilidade das metrópoles, sobretudo nas cidades dos países do Hemisfério Sul, inserindo-as nos debates sobre as questões ambientais e os estilos de desenvolvimento. Isso porque a dinâmica da produção do espaço metropolitano dessas cidades teve como uma das características o uso do solo de atributos ecológicos relevantes pelo mercado imobiliário formal e informal.

Esse processo tem gerado conflitos urbanos envolvendo o poder municipal, populações de baixa renda e o mercado imobiliário, bem como evidenciado o conflito entre o planejamento e a conservação desses territórios. Ou seja, por um lado as políticas públicas têm criado um sistema de proteção ambiental, mas, por outro lado o poder público não é eficiente no sentido de fazer a sociedade e a própria administração, de cumprir com os preceitos legais.

Assim, verificam-se em cidades brasileiras, a exemplo de Recife-PE conflitos em torno de áreas protegidas, como os manguezais, protegidos legalmente, referentes à pressão urbana e sofrem descaracterização, sobretudo pela ocupação da área para urbanização e a sua utilização para a criação de camarões (carcinicultura) ${ }^{3}$ para fins comerciais. Nesse sentido, no Recife tem um exemplo emblemático de uma comunidade situada dentro do

\footnotetext{
${ }^{3}$ Além de Recife, outras cidades em Pernambuco tais como Paulista, Jaboatão, Itamaracá, Igarassu, Goiana, Rio Formoso, Ipojuca, entre outras, tem o problema da criação de camarões em seus manguezais.
} 
manguezal sem condições socioambientais e de habitabilidade e sua população sobrevive da pesca e do camarão.

É importante destacar que as condições socioambientais que compreendem as formas matérias e simbólicas de organização da atividade de pescadores em áreas de proteção ambiental não degradam o meio ambiente. A sustentabilidade é ameaçada quando são destruídos valores e práticas tradicionais em relação ao meio ambiente, nesse caso, a relação de sobrevivência e de exploração dos manguezais para fins comerciais 4 .

Nesse sentido, o presente trabalho intenta refletir sobre o processo de urbanização da comunidade fazendo uma relação entre habitação e sustentabilidade em área de fragilidade ambiental. Tem como principal questionamento: quais as oportunidades que 0 conceito de sustentabilidade coloca à produção da habitação em áreas de fragilidade ambiental?

\section{SUSTENTABILIDADE AMBIENTAL}

A discussão sobre desenvolvimento sustentável ganhou relevância na Conferência das Nações Unidas sobre Meio Ambiente e Desenvolvimento, realizada no Rio de Janeiro em 1992. Porém, os estudos que tratam do desenvolvimento sustentável enfatizam que as preocupações com o meio ambiente surgem por influência das idéias naturalistas dos hippies, na década de 1960, que, defendiam a convivência harmônica com a natureza.

O termo ecodesenvolvimento foi utilizado pela primeira vez em 1973 por conta da polêmica gerada na primeira Conferência das Nações Unidas sobre o Meio Ambiente, em 1972, Estocolmo. Referia-se, inicialmente, à situação das zonas rurais dos países em desenvolvimento e defendia uma gestão mais racional dos ecossistemas locais. O termo

\footnotetext{
${ }^{4}$ Vários estudos foram realizados no Brasil sobre os impactos da implantação de Unidades de Conservação sobre as populações tradicionais ${ }^{4}$, especificamente, pescadores. Podem ser destacadas as contribuições mais recentes de José Geraldo Marques (2001), que fez um estudo sobre conhecimento tradicional da pesca em comunidades litorâneas do Brasil. Outro trabalho é o de Rosemeri Melo e Souza (2007) que estudou a coexistência dos pescadores em Unidades de Conservação de Uso Sustentável, destacando na sua análise, as possibilidades e limitações do monitoramento socioambiental, tendo como estudo de caso a APA Piaçabuçu em Alagoas.
} 
foi ampliado por Ignacy Sachs em um artigo escrito em 1976, considerado um clássico intitulado: "Environment and styles of development", que, além da preocupação com o meio ambiente, incorporou outros aspectos, como as questões sociais, econômicas, culturais, de gestão participativa e ética.

O debate sobre a sustentabilidade impulsionou a criação de novos arranjos institucionais, investimentos em pesquisas ambientais. No entanto, a consolidação de canais de participação e o fortalecimento dos movimentos ambientalistas tanto no âmbito internacional, nacional e local têm-se mostrado insuficiente para traduzir as demandas da sociedade de cunho ambientalista em políticas públicas que promovam um modelo alternativo de desenvolvimento. A falta do aprofundamento da dimensão políticodemocrática das teorias que tratam da sustentabilidade e do desenvolvimento é um dos fatores limitadores da implementação de estratégias de desenvolvimento sustentável, uma vez que se trata de um problema político e de exercício de poder e coloca as instituições político-administrativas, a participação e o processo político no centro da discussão (FREY, 2001).

Zancheti (2002) estuda o desenvolvimento sustentável a partir de suas cinco dimensões: econômica - relacionada aos aspectos quantitativos e qualitativos do processo de produção, distribuição e consumo do produto social; política - refere-se aos relacionamentos humanos no processo de decisão na economia, bem como aos usos dos recursos individuais e coletivos da sociedade; social - a qualidade de vida da população que é derivada dos processos econômicos e políticos; cultural - relacionada às concepções e representações que os indivíduos e grupos fazem de sua inserção na sociedade; e por fim, a dimensão ambiental - referindo-se a forma como os indivíduos percebem e agem sobre a natureza, segundo a dimensão política econômica e social. De acordo com o autor, a sustentabilidade tem despertado a atenção dos gestores e planejadores urbanos, mas ainda é muito difícil a sua prática e entende que para se efetivar é necessária a participação de toda a sociedade. Estas cinco dimensões refletem uma leitura que Sachs (2004) faz do desenvolvimento dentro de uma nova proposta, numa visão holística explicitando a necessidade de inclusão da sociedade no processo de planejamento para alcançar outro desenvolvimento. 
Frey (2001) apresenta três abordagens do desenvolvimento sustentável: i) abordagem econômico-liberal - aposta no mercado como força reguladora do desenvolvimento. É vista pelos seus adeptos, como o melhor mecanismo para garantir a satisfação dos desejos individuais que levaria o mercado a ofertar produtos ecológicos na medida em que os consumidores manifestassem a sua consciência ecológica. Essa concepção parte do pressuposto de que a concorrência, crescimento econômico e prosperidade levariam ao uso racional dos recursos naturais; ii) abordagem ecológico-tecnocrata de planejamento - considera o Estado e suas instituições de regulação e o planejamento como instrumentos essenciais para reduzir ou evitar os efeitos negativos dos processos de crescimento econômico. A dimensão ecológica é o principal elemento e enfoca a compatibilidade do desenvolvimento econômico com a preservação dos recursos naturais. Essa abordagem defende uma concepção de ecologia profunda ${ }^{5}$ que reconhece a interdependência de todos os fenômenos, mas para isso seria necessário que todas as políticas públicas e atividades da sociedade atendessem às exigências da sustentabilidade da natureza; iii) abordagem política de participação democrática abordagem considera a participação da sociedade como elemento fundamental da política ambiental na direção de construir uma sociedade sustentável. O planejamento é orientado pelas necessidades da população e conduzido por ela que também determina as diretrizes políticas. Assim, rompe-se com o compromisso de elite através do processo de descentralização da decisão e da gestão democrática, tornando os cidadãos atores efetivos dos processos decisórios. Para Frey (2001), só uma abordagem participativa tem condições de incorporar as demandas dos diversos segmentos sociais nas políticas públicas, sendo necessária uma democratização ecológica ou ambiental visando soluções dos problemas ambientais

\section{HABITAÇÃO E RISCO AMBIENTAL DA ILHA DE DEUS}

\footnotetext{
${ }^{5}$ O termo ecologia profunda foi criado pelo filósofo norueguês Arne Naess em 1973. É um movimento filosófico e político que questiona os modelos de desenvolvimento e os modos de atender as necessidades humanas incorporando uma reflexão sobre a natureza da relação que o ser humano estabelece com o planeta. O aspecto ecofilosófico do trabalho de Rachel Carson, Primavera Silenciosa (1963) motivou o uso do termo ecologia profunda.
} 
É possível relacionar a sustentabilidade com a produção da habitação. A habitação é um sonho de consumo de toda a sociedade e a forma como a sociedade produz suas habitações vem comprometendo a sustentabilidade das cidades por não respeitar na ocupação do solo as vulnerabilidades e riscos, não considerar importante a eficiência energética e a gestão do ciclo hidrológico, entre outros.

A cidade do Recife, capital de Pernambuco, situada na zona Litoral - Mata da Região do Nordeste, com uma população de 1.422 .905 habitantes, o que corresponde a $43 \%$ da população da Região Metropolitana onde 759 mil pessoas, correspondendo a 53\% da população, residiam em áreas com condições habitacionais inadequadas e desse número, 592 mil habitantes (42\% da população recifense) residiam em 150 mil domicílios situados em Zonas Especiais de Interesse Social - ZEIS (IBGE, 2000). As desigualdades socioeconômicas foram reproduzidas ao longo do processo de desenvolvimento urbano através de políticas públicas elitistas e excludentes. A moradia construída em alagados, palafitas e nas encostas são as formas de acesso à esse bem para parte significativa da população.Ou seja, a ilegalidade da moradia são partes integrante e significativa do desenvolvimento urbano.

A ocupação do solo formal na cidade do Recife ocorreu em áreas planas e secas. As áreas alagadiças e sujeitas a deslizamentos, bem como as de restrições à ocupação, por se tratarem de áreas de fragilidade ambiental, foram ocupadas pela população pobre. Essas áreas não têm valor no mercado de terra, não por não terem condições de regularização. O que implica dizer que a forma de ocupar o solo determina uma posição social.

Nos anos 30, o processo de urbanização se intensifica na cidade do Recife. A população que vinha para a cidade em busca de acesso às oportunidades e serviços não tinha recursos para construírem as suas moradias em áreas planas. Dessa maneira, foram ocupando os alagados, que na época foram chamadas de Mocambos. Em 1939, o Interventor Público Agamenon Magalhães expulsa a população dos mocambos, principalmente os que estavam localizadas no centro da cidade. $O$ argumento era que nessas áreas iriam ser construídas grandes obras públicas, bem como o parcelamento para construção de moradias pela iniciativa privada. Cerca de 12 mil famílias foram morar em outras áreas da cidade, em morros distantes do centro e em áreas que 
representavam riscos para os moradores ou para outros municípios vizinhos. O processo de exclusão e segregação social, combinado com a intensificação da urbanização, promove a degradação do meio ambiente (MOREIRA e SOUZA, 2007).

\subsection{HABITAÇÃO E POBREZA NA COMUNIDADE ILHA DE DEUS}

A ocupação do solo para moradia em áreas alagadas sem condições de habitabilidade reincide diretamente na a sua saúde, tornando a pobreza estrutural ${ }^{6}$. No caso da comunidade Ilha de Deus, um assentamento antigo que remonta os anos 50 , localizada no meio do estuário do Manguezal do Pina. Merece destaque a mobilização e luta da comunidade para garantir o uso dessa área que é protegida por leis ambientais, por se tratar de um ecossistema de relevância para a cidade do Recife. A população conquistou 0 direito de moradia, constituindo-se em uma ZEIS.

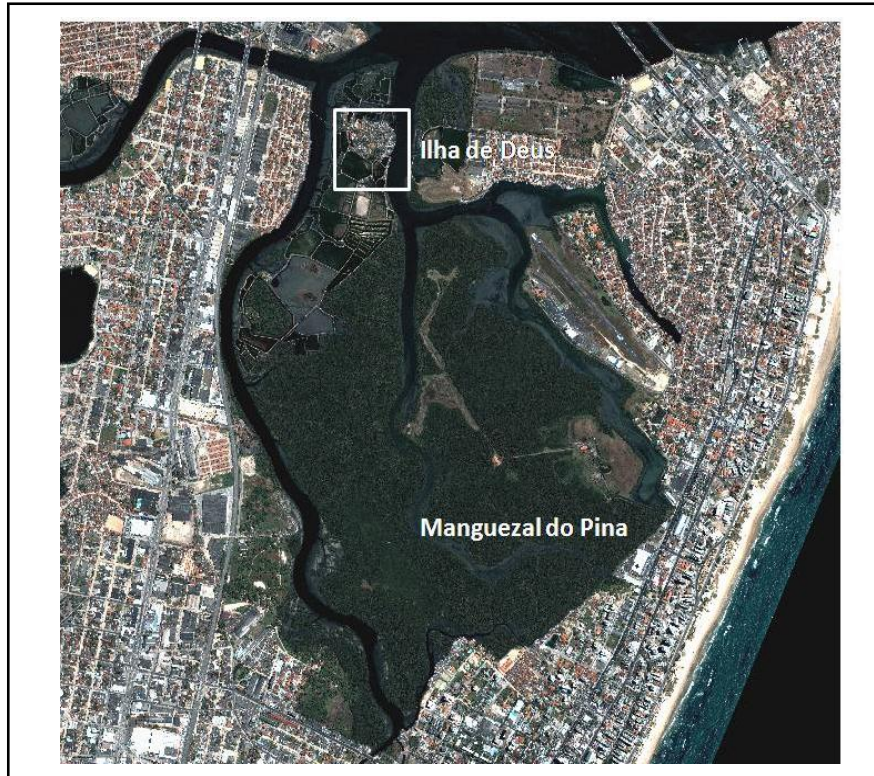

Figura 1 - O Manguezal do Pina e a llha de Deus Fonte: Google Earth, 2009.

A comunidade llha de Deus. A llha de Deus é uma comunidade de pescadores artesanais. Localiza-se na zona Sul da cidade do Recife, entre os bairros do Pina e da Imbiribeira. É cortada pelos rios Pina, Jordão e Tejipió e faz parte da Região Político Administrativa 6 (RPA-6). Está inserida no Manguezal do Pina, ecossistema marcante da cidade do Recife, que é uma Zona Especial de Proteção Ambiental (ZEPA), denominada Parque dos Manguezais (Fig. 1), área de preservação permanente (Art. $2^{\circ}$. "f" da Lei Federal no. 4771/65). A comunidade é uma ZEIS (Zona Especial de Interesse Social).

\footnotetext{
${ }^{6}$ Referem-se aquelas pessoas que sendo pobres (indigentes ou não) não tem as suas necessidades básicas satisfeitas.
} 
O nome da comunidade teve a sua origem no início da ocupação, quando chegaram os primeiros moradores e diante da dificuldade de acesso diziam que a área era uma itha sem Deus. Com a ocupação e a construção de uma capela, um gestor municipal, ao visitar a comunidade, sugeriu a mudança do nome como uma forma de valorizar a riqueza natural, o manguezal, que era a principal fonte de renda dos moradores. Dessa forma, a comunidade aceitou a sugestão e mudou o nome para "Ilha de Deus". De acordo com lideranças, a comunidade surgiu na década de 1950. A população foi chegando e ocupando o local, pela variedade de peixes e crustáceos que existia no manguezal.

\begin{abstract}
Eu vinha aqui pescar. Na época só tinha umas 10 casas. Eu tirava sururu na maré [local onde se localiza a empresa Bacardi] e foi aqui que eu conheci o meu marido. Ele era pescador. A minha casa era de tábua e coberta de palha, como a maioria era. Aqui não existia luz elétrica e a gente comprava a água que era trazida de barco. A gente tinha hora para sair e chegar. Se chegasse depois das 19 horas ficava gritando para o Sr. Firmino ir buscar do outro lado. Todo mundo pagava a ele que cobrava o preço da passagem de ônibus. ${ }^{7}$
\end{abstract}

Gradativamente, a comunidade foi se formando por pessoas que vinham de bairros adjacentes. De acordo com a pesquisa socioeconômica realizada pela FADE/ Governo do Estado em 2007, existem na llha de Deus 348 imóveis, dos quais 312 são domicílios, onde residem 334 famílias com um total de 1.152

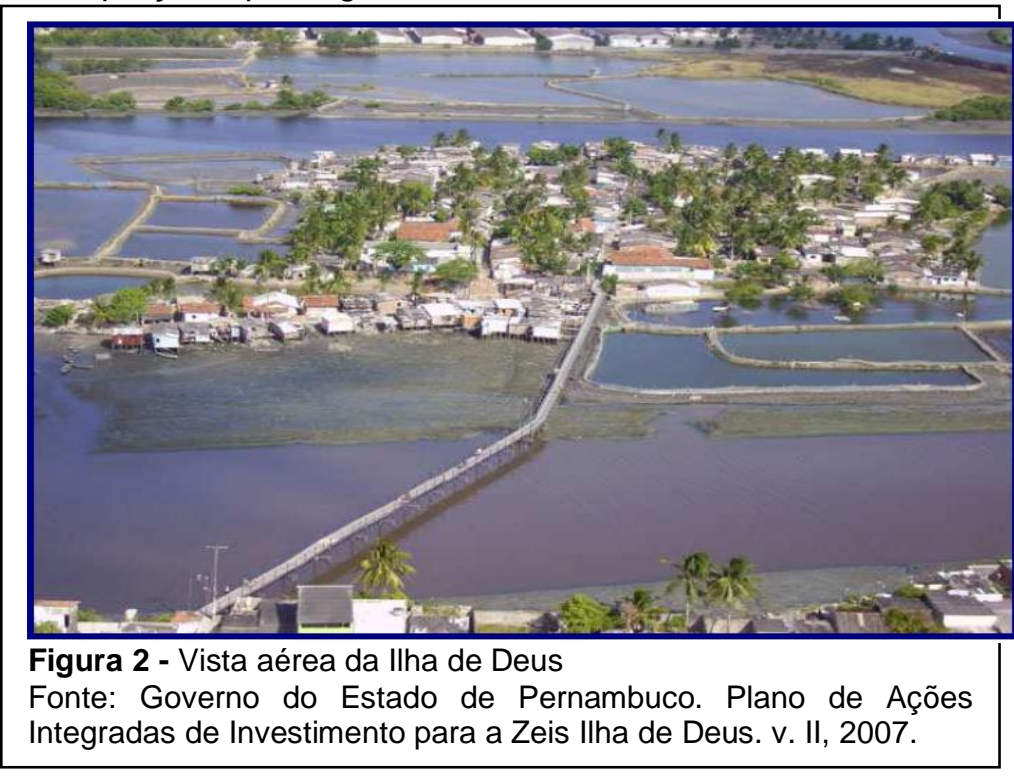
habitantes. A llha foi se modificando com as intervenções dos moradores que aterravam o manguezal para construção de moradias e de viveiros de camarão, constituindo-se em um agravante para meio ambiente. Os moradores estão sujeitos às variações das águas que estão relacionadas ao Manguezal do Pina. A localização da comunidade oferece risco à saúde da população, devido à poluição dos rios do estuário do Manguezal, contaminados pelos esgotos da cidade formal, bem como à exposição dos pescadores e pescadoras a essas águas, já que tiram delas o seu sustento através da atividade de

\footnotetext{
${ }^{7}$ Depoimento de Dona Nicinha, ex-presidente do Conselho de Moradores da llha de Deus.
} 
pesca (Fig. 2). Além das precárias condições de habitação e a carência de infraestrutura urbana, na llha não existe saneamento e os dejetos correm a céu aberto, em direção aos rios. De acordo com o diagnóstico realizado pela FADE/Governo do Estado ${ }^{8}$, a tipologia habitacional predominante é madeira com $49 \%$ das moradias (70 são palafitas) e alvenaria com $46,8 \%$, evidenciando os níveis de pobreza. A renda mensal dos moradores das palafitas é menor que um salário mínimo. A pesquisa destaca que a quantidade de cômodos da moradia está relacionada à renda mensal. A renda mensal da população da Ilha de Deus predominante é de 1/2 a 1 salário mínimo, como mostra o gráfico 1.

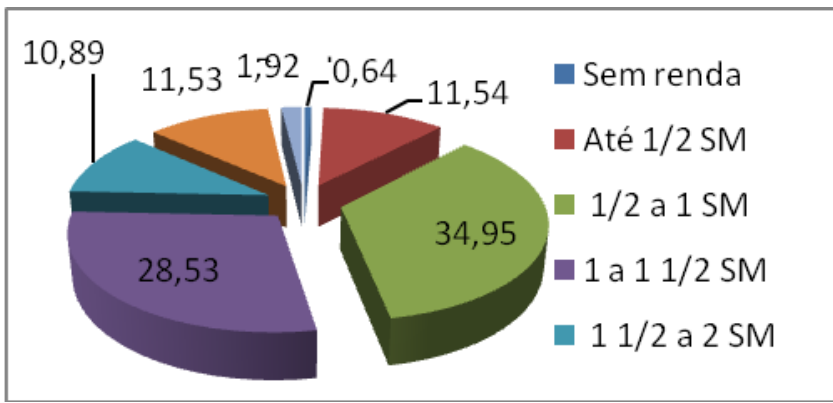

Gráfico 1 - Renda familiar dos moradores da llha de Deus

Fonte: Dados do diagnóstico realizado pela FADE/ Governo do Estado, 2007.

Além da pesca, os moradores desenvolvem outras atividades profissionais, tais como o comércio, construção civil, serviços domésticos entre outros. Outra atividade começa a surgir na comunidade, que é o artesanato. Hoje existe um grupo de 15 adolescentes que confeccionam produtos feitos com a casca do marisco. Para a líder do grupo, toda a população tem uma relação com a pesca:

Observe o chão da nossa comunidade. $O$ aterro é feito com a casca do marisco e sururu. A gente não tinha pensado que poderia ganhar dinheiro com o que os pescadores e pescadoras jogavam fora. Até que a mulher do atual governador fez a observação e nos ofereceu um curso. Fizemos, produzimos e já vendemos em três Feiras de artesanato, a FENEART. Fazemos uma verdadeira obra-prima. ${ }^{9}$

Como foi dito anteriormente, a comunidade está inserida no Manguezal e sujeita à variação da maré, que alaga toda a área, e à exposição de doenças de veiculação hídrica. Os dados da pesquisa realizada pelo Governo do Estado destacam o nível de pobreza e o

\footnotetext{
${ }^{8}$ A Fundação de Apoio ao Desenvolvimento da Universidade Federal de Pernambuco - FADE elaborou os diagnósticos da llha de Deus para municiar a elaboração do Plano de Ação Integrada de Investimento da ZEIS Ilha de Deus
}

\footnotetext{
${ }^{9}$ Depoimento de Fátima, liderança e coordenadora do grupo de artesanato da llha de Deus.
} 
grau de exposição dos moradores da llha de Deus - configura-se em uma situação de desigualdade e vulnerabilidade socioambiental.

Apesar de a comunidade não apresentar condições favoráveis para uma moradia digna, devido às condições de vulnerabilidade ambiental, os moradores acreditam que é lá o seu lugar. De acordo com uma as lideranças entrevistadas, ninguém pensa em sair da comunidade, pois a llha "oferece o alimento que é tirado do mangue. Se é arriscado viver aqui, é aqui que a gente fica e ninguém nos tira daqui." Esse espírito de pertença da comunidade propiciou a organização dos moradores em torno do direito de permanecer na llha, mesmo estando inserida em uma área de proteção ambiental. Apesar de todas as leis ambientais municipais e federais, ${ }^{10}$ a comunidade conseguiu manter-se no local evidenciando a ineficiência do Estado no controle das áreas de preservação ambiental e na elaboração de políticas públicas que atendam as demandas por habitação e preservação do meio ambiente. Assim, a mobilização da comunidade garantiu a redifinição do contorno da Área de Proteção Ambiental o que possibilitou a sua transformação em Zona Especial de Interesse Social - ZEIS através de Lei Municipal.

\section{A CONQUISTA DO DIREITO DE MORAR NA ILHA E A AÇÃO DO ESTADO}

O Plano de Regularização das Zonas Especiais de Interesses Sociais - PREZEIS, programa de regularização das favelas regulamentada por lei municipal em 1987 possibilita aos moradores o direito de solicitar a legalização da área em que moram, como também o controle no acompanhamento do processo de urbanização. O PREZEIS tornouse referência para a gestão municipal no Brasil.

\footnotetext{
${ }^{10}$ Lei 4.771, de 15 de setembro de 1965 - institui o Código Florestal; Lei 9.985, de 18 de julho de $2000-$ institui o Sistema Nacional de Unidades de Conservação da Natureza; (SNUC); Decreto ํo 5.758, de 13 de abril de 2006 - institui o Plano Estratégico Nacional de Áreas Protegidas; Decreto no 6.040, de 07 de fevereiro de 2007 - institui a Política Nacional de Desenvolvimento Sustentável de Povos e Comunidades Tradicionais
} 
A ZEIS é um dos instrumentos de regularização fundiária na Lei do Parcelamento do Solo Urbano (Lei 9.85 de 29/01/99) e no Estatuto da Cidade (alínea "f", do inciso $V$ do artigo 40). O status de ZEIS consolidou a comunidade na llha de Deus. Assim, o Governo do Estado, em parceria com a Prefeitura do Recife, vem discutindo com a população o Projeto Urbanístico para a llha (Fig. 3). O reconhecimento institucional do direito à moradia e de participar decidindo sobre os interesses coletivos, tem possibilitado administrar os conflitos em torno da urbanização da llha de Deus. A ZEIS Ilha de Deus não passou pelo mesmo processo das demais. Ao ser delimitada como uma ZEIS, instalase uma Comissão de Urbanização e Legalização da ZEIS - COMUL que é constituída por representantes do executivo municipal, da sociedade e entidades do Movimento Popular para discutir sobre as intervenções para a regularização urbanística, os processos de normatização (estabelecimento de parâmetros urbanísticos) e de controle urbanístico. No caso da llha de Deus, por se tratar de um compromisso político, o processo teve as suas particularidades e não foi instalada a COMUL. Assim, o Plano urbanístico da llha de Deus não é um plano do PREZEIS.

A legislação que regulamenta as ZEIS indica como um dos critérios para delimitar uma comunidade em ZEIS é não estar em áreas de proteção permanente, como não é o caso da llha. Por outro lado, uma população que habita um local há mais de 50 anos adquiriu 0 direito de permanecer no local, direito assegurado por lei. $\mathrm{O}$ processo de urbanização da Ilha não pode ser visto sob os mesmos parâmetros de outras comunidades. Na llha,

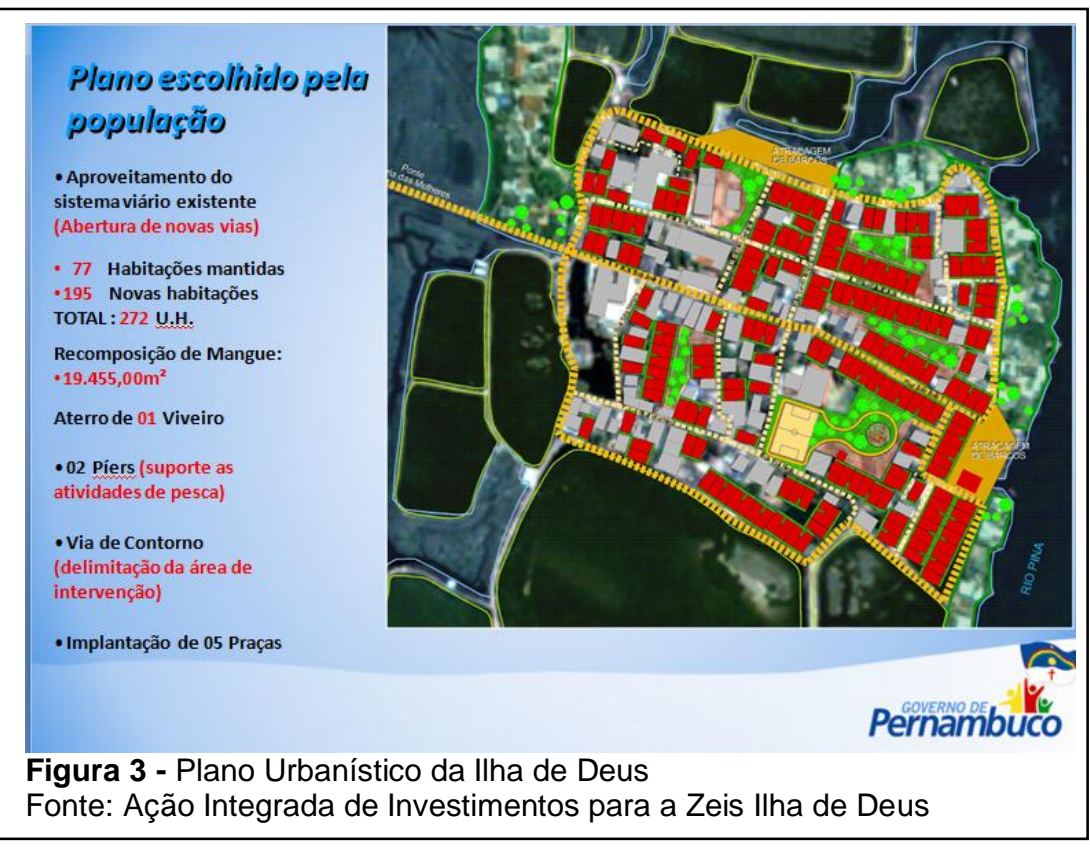
há de se considerarem as práticas sociais dos moradores em relação ao meio ambiente. 
O Governo do Estado em parceria com a prefeitura está vias de urbanizar toda a comunidade. Novas casas serão construídas com toda a infraestrutura urbana. O Plano urbanístico está sendo debatido com a população. A proposta é também orientar pescadores para sua atividade, a pesca, seja sustentável.

\section{Considerações finais}

Esse trabalho teve como objetivo refletir sobre as possibilidades que o conceito de sustentabilidade coloca à produção da habitação em áreas de fragilidade ambiental, tendo como campo empírico a comunidade llha de Deus, Recife, PE.

As condições socioambientais das favelas do Recife evidenciam a ineficiência e o caráter excludente da política habitacional, bem como a falta de diálogo entre o planejamento urbano e a política ambiental, especialmente, em se tratando de assentamentos em áreas de atributos ecológicos relevantes para a cidade.

Embora não tenham sido estudados todos os dados que evidenciam a situação, os que foram apresentados caracterizam as condições socioeconômicas dos moradores da llha e evidenciaram a relação renda e tipologia habitacional, onde os mais pobres estão localizados em palafitas e mais expostos a vetores de doenças transmissíveis e com os maiores níveis de pobreza e privação social, configurando uma situação de vulnerabilidade socioambiental.

O caso chama a atenção para a necessidade de pensar a intersetorialidade das políticas públicas na perspectiva de redução da vulnerabilidade socioambiental, concentrando-se na política de habitação - urbanização das favelas- articulando com as políticas saneamento e meio ambiente. Nesse sentido, a urbanização de favelas "podem ser vistas também como políticas ambientais, lidando com os riscos a que estão expostos os grupos mais vulneráveis da população urbana" (ALVES e TORRES, 2006).

O processo da llha de Deus reforça as idéias de Acselrad (2006) quando destaca que os sujeitos são vulneráveis porque são vítimas de uma proteção desigual. Assim, é a responsabilidade do Estado, e não a incapacidade dos sujeitos sociais de responderem 
aos riscos, o que os tornam vulneráveis. Garantir aos moradores da llha de Deus uma moradia digna, água apropriada para o consumo, melhor aproveitamento dos recursos naturais disponíveis de forma sustentável é papel do Estado. Os moradores da llha são vítimas de uma proteção desigual.

Tomando como referência as ideias de Frey (2001), a abordagem política de participação democrática abre a possibilidade de produção da habitação em área de fragilidade ambiental, que implica no envolvimento do poder público e população nesse processo. A comunidade apesar de situar-se em uma área que apresenta riscos de alagamentos, a vontade política do Estado e o reconhecimento da população do seu direito, aliado ao uso de tecnologias e à educação ambiental está tornando possível a construção de moradias com condições de habitabilidade.

\section{Referências}

ACSELRAD, Henri. Vulnerabilidade ambiental, processos e relações. 2006. Disponível em:<

http://www.justicaambiental.org.br/projetos/clientes/noar/noar/UserFiles/17/File/Vulnerabili dadeAmbProcRelAcselrad.pdf >. Acesso em 01 ago. 2009.

ALVES, Humberto Prates da Fonseca; TORRES, Haroldo da gama. Vulnerabilidade socioambiental na cidade de São Paulo: uma análise de famílias e domicílios em situação de pobreza e risco ambiental. São Paulo em Perspectiva, São Paulo, v. 20, n. 1, p. 4460 jan./mar. 2006.

FREY, Klaus. A dimensão político-democrática nas teorias de desenvolvimento sustentável e suas implicações para a gestão local. Ambiente e Sociedade, ano IV, n. 9, p. 115-148, 2001.

MOREIRA, Clara Gomes; SOUZA, Maria Ângela de Almeida. Ilha de Deus no Recife, Brasil: Um caso emblemático do direito à moradia conquistado em área de risco legalmente preservada. 2008. Disponível em: http://www.invi.uchile.cl/derechociudad/ponencias/Jornada/Panel\%203/4.\%20Gomes\%20 Moreira,\%20De\%20Almeida.pdf. >. Acesso em: 20 maio 2009.

SACHS, Ignacy. Desenvolvimento: includente, sustentável, sustentado. Rio de Janeiro: Garamond, 2004.

SANTOS, Milton. A urbanização brasileira. 3. ed. São Paulo: Hucitec, 1996. 


\section{Periódica Eletrânica

ZANCHETI, Silvio Mendes. O desenvolvimento sustentável urbano. In:

(Org.).

Gestão do patrimônio cultural integrado. Centro de Conservação Integrada Urbana e Territorial. Programa de Pós-Graduação em Desenvolvimento Urbano - UFPE. Recife: Ed. Universitária da UFPE, 2002. 